\title{
Ser Aluno e Paciente: Um Novo Olhar Sobre o Acesso Pedagógico Hospitalar
}

\author{
Ser un Alumno y Paciente: Uma Nueva Vista Al Acceso Pedagogico Del \\ Hospital
}

\author{
Being a Student and a Pacient: A New Look At Hospital Pedagogical \\ Acess
}

Amanda Flores Scremin ${ }^{1}$

Jane Schumacher ${ }^{2}$

\begin{abstract}
Resumo
O estudo busca discutir sobre as atividades de ensino e aprendizagem prática, de apoio pedagógico lúdico ao paciente, garantindo seu desenvolvimento e contribuindo para a sua reinserção e adaptação no ambiente escolar após a alta. Atividade é desenvolvida no o Serviço de Hemato-Oncologia do HUSM no Centro de Tratamento da Criança com Câncer (CTCriaC), que dispõe de equipe, constituída de médicos, profissionais de enfermagem, nutricionista e psicóloga e fisioterapeuta, é a unidade de internação de crianças e adultos jovens ( 0 a 20 anos) com leucemias, tumores sólidos e distúrbios hematológicos, que realiza assistência multiprofissional no diagnóstico, tratamento, manutenção e cuidados paliativos, com o objetivo de melhorar a qualidade de vida dos pacientes, reinserindo-os na vida social (escola, família, lazer, etc.). Através das ações, permite aperfeiçoar a aprendizagem complementar dos acadêmicos, por meio de atividades prático-teóricas de forma lúdica, realizadas junto aos pacientes do Serviço de CTcriaC, viabilizando assim, mais uma forma de aprendizado complementar aos licenciados. As práticas relacionadas às vivências extracurriculares no setor, viabilizam o acesso dos alunos permitem que os mesmos adquiram conhecimentos complementares sobre ações pedagógicas desenvolvidas no ambiente hospitalar em prol do processo de aprendizagem da criança hospitalizada possibilitando que ela não perca o vínculo com a instituição escolar que frequenta, contribuindo, portanto, para a formação dos alunos e as ações pedagógicas desenvolvidas no ambiente hospitalar, em prol do processo de aprendizagem da criança hospitalizada possibilita que ela não perca o vínculo com a instituição escolar que frequenta.
\end{abstract}

Palavras Chave: Atendimento pedagógico hospitalar, ensino, aprendizagem, lúdico.

\section{Resumen}

El estudio objetiva discutir actividades de enseñanza y aprendizaje práctica, proporcionando apoyo pedagógico al paciente, garantizando su desarrollo, y contribuyendo para su reintegración y adaptación en el ambiente escolar después del alta. La actividad se desarrolla en el Servicio de Hemato-Oncología del HUSM en el Centro de Tratamiento de Niños con Cáncer (CTCriaC), que cuenta con un equipo formado por médicos, profesionales de enfermería, nutricionista, psicólogo y fisioterapeuta, es la unidad de internación de niños y jóvenes adultos ( 0 a 20 años) con leucemias, tumores sólidos y disturbios hematológicos, que realizan asistencia multiprofesional en el diagnóstico, tratamiento, mantenimiento y cuidados paliativos, con el objetivo de mejorar la calidad de vida de los pacientes, reinsertiéndolos en la vida social (escuela, familia, ocio, etc.). A través de las acciones, permite mejorar el aprendizaje complementario de los académicos, por medio de actividades prácticas y teóricas de forma lúdica, realizadas con los pacientes del Servicio CTCriaC, posibilitando así otra forma de aprendizaje complementario a los egresados. Las prácticas relacionadas con las experiencias extracurriculares en el sector hacen que el acceso de los alumnos les permita adquirir conocimientos complementarios sobre acciones pedagógicas desarrolladas en el ambiente hospitalario a favor del proceso de aprendizaje del niño hospitalizado, para que no pierda el vínculo con la institución escolar que atiende, contribuyendo así a la formación de los alumnos ya las acciones pedagógicas desarrolladas en el ambiente hospitalario, en pro del proceso de aprendizaje del niño hospitalizado, posibilita no perder el vínculo con la institución escolar que atiende.

\footnotetext{
${ }^{1}$ Graduanda, UFSM; RS; Brasil; screminamanda@ outlook.com

${ }^{2}$ Doutorado pelo Programa de Pós Graduação em Educação da UFRGS; RS; Brasil; mixjanepereira@yahoo.com.br
} 
Palabras Clave: Cuidado pedagogico hospitalario, educación, aprendizaje, ludico.

\section{Abstract}

The present study aims to discuss teaching activities and practical learning, providing pedagogical support to the patient, ensuring their development, and contributing to their reintegration and adaptation in the school environment after discharge. Activity is developed in the HUSM Hemato-Oncology Service at the Center for the Treatment of Children with Cancer (CTCriaC), which has a team consisting of doctors, nursing professionals, nutritionists, psychologists and physiotherapists, is the unit of hospitalization of children and young adults ( 0 to 20 years old) with leukemias, solid tumors and hematological disorders, who perform multiprofessional assistance in diagnosis, treatment, maintenance and palliative care, aiming to improve patients' quality of life, reinserting them into social life (school, family, leisure, etc). Through the activities, it allows to improve the complementary learning of the academics, through practical and theoretical activities in a playful way, performed with the patients of the CTcriaC Service, thus making possible another way of learning complementary to the graduates. The practices related to the extracurricular experiences in the sector allow the students to acquire complementary knowledge about pedagogical actions developed in the hospital environment in favor of the learning process of the hospitalized child, so that it does not lose the link with the school institution that attends, thus contributing to the training of students and the pedagogical actions developed in the hospital environment, in favor of the learning process of the hospitalized child, makes it possible for it not to lose the bond with the school institution that it attends.

Key Word: Hospital pedagogical care, education, learning

\section{Educa ação, lúdica, hospitalar}

Relatar a experiência, o trabalho pedagógico com Crianças e adolescentes Hospitalizados no HUSM- RS é reportar-se ao contexto que surgiu as ações que serão aqui discutidas e que estão sendo implementadas. Contexto que envolve a formação dos alunos acadêmicos do Curso de Licenciatura em Educação Especial Noturno da UFSM, o contexto escolar e o ambiente hospitalar.

Atuar no contexto hospitalar é ainda considerada uma nova área, distante dos âmbitos educacionais comuns, que assegura os direito que todos possuem à educação, principalmente aqueles que, devido a uma enfermidade, precisam ficar ausentes da escola em virtude de sua hospitalização, conforme a Resolução $\mathrm{n}^{\text {o }}$ 41 de outubro de 1995, no item 9, o qual salienta o "Direito de desfrutar de alguma forma de recreação, programas de educação para a saúde, acompanhamento do currículo escolar durante sua permanência hospitalar".

Conforme Esteves (2008) este ramo surgiu na cidade de Paris da França por volta de 1935, onde deparou-se com a demanda de promover o atendimento educacional das crianças e adolescentes com doenças que as impediam de frequentar a escola, e se popularizou no fim da Segunda Guerra Mundial, com o fato de um grande número de educandos terem sido atingidos pelo conflito, logo estes necessitavam de atendimento especializado.

Já no Brasil de acordo com Lima e Paleologo (2018) surgiu o movimento na década de 50 na cidade do Rio de Janeiro na qual permanece atualmente com o atendimento a crianças hospitalizadas. Segundo Matos e Mugiatti (2007), existe no estado do Paraná, um projeto 
direcionado na área da educação e saúde, nomeado "Hospitalização Escolarizada", que influenciou na implantação da Pedagogia Hospitalar no Brasil, com suporte das Secretarias da Educação e Saúde.

Com estas ações, o Ministério da Educação vê a necessidade de produzir um documento nesta área com o auxílio da Secretaria Especial, que contém estratégias e orientações para proporcionar a promoção do atendimento pedagógico em classes hospitalares.

O Brasil reconheceu a legislação por meio do Estatuto da Criança e do Adolescente Hospitalizado, a Resolução n". 41 de outubro e 1995, no item 9, o "Direito de desfrutar de alguma forma de recreação, programas de educação para a saúde, acompanhamento do currículo escolar durante sua permanência hospitalar. Portanto, a legislação assegura aos educandos em situação hospitalar que sejam atendidos de acordo com suas especificidades.

O atendimento Pedagógico Hospitalar tem a responsabilidade e a obrigação de garantir apoio educacional não somente às crianças que têm transtornos do desenvolvimento, mas também às crianças e aos adolescentes que se encontram em situações de riscos ao desenvolvimento físico, psíquico, imunológico, e que se encontram afastados do convívio social e escolar.

Em 2002, é promulgado outro documento intitulado "Classe Hospitalar e Atendimento Pedagógico Domiciliar: estratégias e orientações”, publicado pelo MEC (BRASIL, 2002), com o propósito específico de estruturar ações, políticas de organização do sistema de atendimento educacional em ambientes hospitalares e domiciliares.

Compreende-se no âmbito desta proposta que, o objetivo do atendimento Pedagógico no contexto Hospitalar é defender o direito de toda criança e adolescente, lutando pelo respeito e cidadania, onde todos devem ter oportunidades iguais, buscando superar as dificuldades e possibilitar um ambiente propício para o aprendizado, em que busca integrar o doente em sua situação hospitalar.

É notório que os acadêmicos prepararam os conteúdos e, dentro do próprio hospital, realiza as atividades propostas de forma adequada a cada paciente, para que o fato de estarem hospitalizadas não seja ainda mais doloroso e acabe prejudicando tanto sua saúde quanto seus estudos.

A prática deste acadêmico se dá através das variadas atividades lúdicas e recreativas como a arte de contar histórias, brincadeiras, jogos, dramatização, desenhos e pinturas, a continuação dos estudos no hospital. 
Portanto o atendimento Pedagógico Hospitalar e seus segmentos têm grande importância no desenvolvimento da criança enferma, todavia, há um longo percurso a ser percorrido para que essa tarefa conquiste seu espaço e real conhecimento por toda a sociedade, é um ramo da educação que proporciona à criança e ao adolescente hospitalizado uma recuperação mais tranquila, através de atividades lúdicas, pedagógicas e recreativas.

Além disso, previne o fracasso escolar, que nesses casos, é gerado pelo afastamento da rotina escolar. Pretende integrar o doente no seu novo modo de vida tão rápido quanto possível dentro de um ambiente acolhedor e humanizado, mantendo contatos com o meio exterior privilegiando as suas relações sociais e reforçando os laços familiares promove um elo da criança ou do adolescente hospitalizado com o mundo que ficou fora do hospital.

Cabe nos perguntar como a Escola, o Hospital e os Cursos de Licenciatura atuam no atendimento pedagogia com crianças e adolescentes hospitalizados? Como estes três espaços Escola, Hospital e Curso de Licenciatura podem contribuir com crianças e adolescentes em hospitalização? Partindo deste pressuposto o objetivo deste trabalho é discutir como o trabalho pedagógico de acompanhamentos das Crianças e adolescentes Hospitalizados do HUSM- RS poderá contribuir comum a recuperação mais tranquila, através de atividades lúdicas, pedagógicas e recreativas, realizadas por alunas do Curso de Educação Especial da UFSM.

É notório que a escola, o hospital e a formação dos Licenciados podem agregar conhecimentos frente às ações previstas no projeto Institucional de Vivencias, rompendo contextos institucionalizados através o apoio pedagógico lúdico que vem realizando desde junho de 2018 com crianças e adolescentes hospitalizados.

Este processo inicialmente nos reportara ao contexto que surgiu as inquietações que serão aqui discutidas, buscando responder questões que acompanham todo o processo de vivência: Na Escola? No Hospital? Na Formação do Licenciado? Estes são os três pilares bases da proposta das ações junto a Unidade do Centro de Tratamento de Crianças com câncer do Hospital Universitário de Santa Maria- RS.

Ao falarmos de crianças e adolescentes que estão hospitalizadas, sabemos que estamos mencionando sujeitos que estão em momento significativo de desenvolvimento humano, onde as atividades educativas e de convívio social está entre uma das ações mais afetadas neste processo. Entender qual o comprometimento da escola com estes sujeitos, é nossa primeiro questão relevante. Ao pensarmos no contexto escolar, nos reportamos a um espaço com salas de aula, estudantes e professor, sem falar do quadro e filas.

Neste entendimento, Araújo (2008) nos ajuda a entender a escola como instituição 
educativa, assume o ensinar e aprender, atividades centrais na interlocução entre os referidos sujeitos; medeiam estes os métodos e as técnicas de ensino, as tecnologias educativas, a avaliação, bem como o espaço físico (comumente chamado de sala de aula), por meio dos quais se buscam perseguir objetivos e finalidades.

Nesta compreensão Silva (2008) colabora afirmando que a dimensão de organização do processo educativo, tempo e espaço de aprendizagem, de desconstrução e construção não se vincula a um espaço específico, uma vez que a aula, pode realizar-se em espaços não convencionais, para além de sala retangular com cadeiras e mesas dispostas, com um quadro de giz na parede e um espaço central para o professor.

Portanto, acreditamos na educação como prática social voltada para a emancipação, onde os sujeitos são protagonistas do processo educativo, assim o apoio pedagógico, por nós realizado por meio de objetivos, conteúdos, procedimentos devidamente planejados, são necessários para nossa ação pois, como em qualquer outro espaço educativo, deseja-se alcançar a aprendizagem dos sujeitos envolvidos.

Entendemos que as ações pedagógicas não deve ter somente um caráter recreativo ou, meramente, humanitário, constitui-se de uma propostas realizada mediante diálogo nunca esquecendo dos princípios éticos da profissão do futuro Licenciado, para não "invadir a privacidade do outro e expô-la aos demais" como mencionada Freire (1996).

A experiência possibilita ouvir os sujeitos e a família, conhecer as suas curiosidades, pois concordamos com Freire (1996) que é a curiosidade que faz "perguntar mais, conhecer, atuar, mais perguntar, reconhecer".

E quanto ao contexto do hospital? Conforme Ceccim (1999),para a criança e para o adolescente internado o hospital, representa um ambiente desconhecido, restrito das possibilidades do seu cotidiano como brincar, conviver com amigos e familiares. Nesta questão que o contexto hospitalar tem despertado interesse quando se trata de analisar e intervir nos possíveis efeitos sobre o processo do desenvolvimento e da aprendizagem .

Conforme o Ministério da Saúde (1997), o hospital é parte integrante de uma organização médica e social, cuja função básica consiste em proporcionar à população assistência médica integral, curativa e preventiva, inclusive domiciliar, constituindo-se também em centro de educação, capacitação e de pesquisas em saúde.

Em relação às propostas educacionais oficiais do Ministério da Educação, à Pedagogia Hospitalar no Brasil encontramos como referência o documento "Classe Hospitalar e Atendimento Pedagógico Domiciliar: Estratégias e Orientações.” (BRASIL, 2002).

Colaborando com esta proposta Masetti (2003) salienta que, a humanização no 
contexto hospitalar, acontece através de "boas misturas" do diálogo entre diferentes atuações, em especial de sentir-se estar no espaço hospital, lidando com a fragilidade, onde todas as atuações convergem para saúde do paciente.

O Conselho Nacional dos Direitos da Criança e do Adolescente (1995) garantem para esta parcela da população, "o direito de desfrutar de alguma forma de recreação, programas de educação para a saúde e acompanhamento do currículo escolar, durante a sua permanência hospitalar".

Já o Conselho Nacional da Educação. Resolução CNE/CBE, n. 2, (2001) institui normas para a educação de alunos com necessidades especiais em todas as suas etapas e modalidades e refere-se à classe hospitalar como "destinada a prover, mediante atendimento especializado, a educação de alunos impossibilitados de frequentar as aulas em razão de tratamento de saúde que implique na internação hospitalar ou atendimento ambulatorial'.Com base no entendimento exposto, surge o contexto da ação proposta.

De acordo com Projeto Político pedagógico do curso de Licenciatura em Educação Especial da Universidade Federal de Santa Maria (2018), o profissional "Como Professor de Educação Especial, o cursista terá competências para identificar as condições dos alunos da Educação Especial, valorizando a educação inclusiva.".

Devendo flexibilizar a ação pedagógica nas áreas de atuação e avaliando a eficácia do processo educativo.

"O diplomado necessitará dominar estratégias pedagógicas que viabilizem a transmissão do conhecimento para os alunos nas etapas de Educação Infantil e Anos Iniciais do Ensino Fundamental. Ainda, o diplomado deverá ter competência para atuar como professor nos diferentes espaços, formais e não formais, de aprendizagem desenvolvendo práticas necessárias para o desenvolvimento dos alunos da Educação Especial, no caso da surdez e deficiência mental, sempre respeitando a condição de escolarização desses sujeitos."

Assim mostraremos os contextos de ação onde desenvolvemos ações, através do apoio pedagógico pertinente a realidade em questão.

\section{Contexto Investigado: O CTCriaC do Hospital Universitário de Santa Maria}

No Hospital Universitário de Santa Maria na Universidade Federal, através da Gerência de Ensino e Pesquisa/GEP tem as atividades de ensino, pesquisa e extensão práticas no hospital. A existência do Projeto Institucional de Extensão em Ensino de atividades de ensino e aprendizagem prática nos serviços do HUSM, no projeto de Vivências, os alunos de várias áreas realizam suas atividades, com o acompanhamento de um profissional na área de interesse, contribuindo desta forma para formação dos acadêmicos e futuros profissionais. 
Assim surge o Subprojeto EDUCA-AÇÃO-LÚDICA HOSPITALAR no primeiro semestre de 2018. O Projeto é estruturado mediante a coordenação de uma professora do Departamento de Metodologia de Ensino do Centro de Educação, professores e profissionais do serviço de Hemato- Oncologia - Unidade do Centro de Tratamento a Criança com Câncer CTcriaC e, o Núcleo de Educação permanente em Saúde do HUSM, sendo efetivado por cinco (5) acadêmicos voluntários do Curso de Licenciatura em Pedagogia da UFSM

O Subprojeto, pretende aperfeiçoar a aprendizagem dos acadêmicos do Curso de Licenciatura através do Apoio pedagógico Hospitalar, garantir a continuidade da escolarização das criançasladolescentes em situação de internação no CTcriaC, contribuindo para a sua reinserção e adaptação no ambiente escolar após a alta através do desenvolvimento de atividades de ensino e aprendizagem, de apoio pedagógico lúdico.

\section{Diagnóstico da situação da atuação}

As atividades de ensino e aprendizagem prática, de apoio pedagógico lúdico as crianças e adolescentes, busca garantir seu desenvolvimento, e contribuindo para a sua reinserção e adaptação no ambiente escolar após a alta. Essas atividades são desenvolvidas no o Serviço de Hemato-Oncologia do HUSM no Centro de Tratamento da Criança com Câncer (CTCriaC), que dispõe de equipe, constituída de médicos, profissionais de enfermagem, nutricionista e psicóloga e fisioterapeuta.

É uma unidade de internação de crianças e adultos jovens ( 0 a 20 anos $)$ com leucemias, tumores sólidos e distúrbios hematológicos, que realiza assistência multiprofissional no diagnóstico, tratamento, manutenção e cuidados paliativos, com o objetivo de melhorar a qualidade de vida dos pacientes, reinserindo-os na vida social (trabalho, família, lazer, etc.).

A proposta visa assessorar crianças e jovens que não estão em condições de frequentar a escola. Sabemos do nosso papel neste contexto de atuação, pois auxiliamos a criança/adolescente aluno para que dê continuidade aos estudos e assim não seja prejudicado devido à condição que se encontra.

Essas crianças/jovens vivem um momento difícil de sua vida e essa situação tende a alterar seu desenvolvimento, é nesse âmbito que os acadêmicos do curso de Pedagogia assume um papel de agente transformador, de levar a esses pacientes atividades que proporcionem a continuação de sua aprendizagem com conteúdos escolares e lúdicos. Pois conforme Matos (2006) “A pedagogia hospitalar aponta, ainda mais um recurso contributivo 
para a cura. Favorece a associação do resgate, de forma multidisciplinar, da condição inata do organismo, de saúde e bem-estar, ao resgate da humanização e da cidadania.".

Segundo Fonseca(2018) ainda não se pode afirmar se esses serviços realmente já se concretizaram nos hospitais, mas vale ressaltar que mesmo com todas essas leis a favor da educação em hospitais, sua efetivação dependerá da disponibilidade dos hospitais, ou seja, se haverá espaço físico e o tipo de convênio.

Neste entendimento é que planejamos as atividades que serão ministradas e levamos em conta não só o ambiente (seja no leito ou sala conjunta de atendimento), mas o contexto do aluno, tendo em conta o nível de aprendizagem e faixa etária, na qual geralmente se diversifica nesses ambientes.

Já é notório que estejamos devidamente habilitados a trabalhar com a diversidade e diferentes experiências, para que assim possamos identificar as necessidades educacionais de cada paciente. Neste entendimento Pimenta (1997) destaca que o professor pode utilizar da ludicidade, possuindo roupas diferenciadas para não assemelhar-se com o médico. Sua linguagem deve ser de maneira informal ao desempenhar seu trabalho.

Também concordamos com Matos e Mugiatti (2018) que ressaltam o valor da cooperação de equipes médicas, psicólogos e assistentes sociais para com o trabalho que estamos realizando professor, afim de assegurar uma conciliação das situações problematizadas, alcançando níveis de melhorias tanto na saúde, quanto na aprendizagem.

Sabemos que poderemos utilizar vários métodos para propiciara aprendizagem das crianças/adolescentes que se encontram na unidade, dentre elas o lúdico é o que utilizamos, por meio das brincadeiras, jogos, para que assim essas crianças/ adolescentes/ pacientes exercitem sua criatividade e também sintam prazer em estudar.

Aqui trazemos os ensinamentos de Froebel (2001) que destaca a importância do brincar. A brincadeira é a atividade espiritual mais pura [...] Ela dá alegria, liberdade, contentamento, descanso externo e interno, paz com o mundo... O Brincar em qualquer tempo não é trivial, é altamente sério e de profunda significação.

Já percebemos que o brincar é importante para o desenvolvimento das crianças, pois com esta prática elas estão desenvolvendo suas capacidades e possuir uma melhor qualidade de vida, como diz Froebel (2001) que o brincar é necessário e sério e que possibilita o aprimoramento da aprendizagem da criança.

Nossas ações pedagógicas têm um começo e fim no mesmo dia, já que em determinados casos, os pacientes podem ter alta, ou devido ao tratamento e cirurgias entre 
outras atividades da rotina do hospital. Já sabemos da importância de oferecer uma rotina mesmo que em alguns casos não seja possível sua efetivação.

Para isso é realizamos um levantamento de dados sobre o paciente, como: sua idade, sua condição cognitiva e motora, para que possa ser trabalhada a possibilidade de brincar, manipular objetos, e o convívio social. Conforme Fonseca (2003), o professor é antes de tudo um mediador das interações da criança com o meio hospitalar.

\section{Intervenção Proposta: a realização do apoio pedagógico hospitalizado}

Através das ações de apoio pedagógico realizado, tem-se momentos que permite aperfeiçoar a aprendizagem complementar por meio de atividades prático-teóricas de forma lúdica, realizadas junto aos pacientes do Serviço de CTCriaC, viabilizando assim, mais uma forma de aprendizado complementar aos licenciados.

As práticas relacionadas às vivências extracurriculares no setor, viabilizam o acesso dos alunos/sujeitos/pacientes permitindo que os mesmos adquiram conhecimentos complementares sobre ações pedagógicas desenvolvidas no ambiente em prol do processo de aprendizagem possibilitando que estes não percam os vínculo com a instituição escolar que frequenta.

Pode-se compreender que esta atuação possui fundamental relevância para as crianças/adolescentes/ pacientes que se encontram em situações hospitalares. Esta ação pedagógica trabalha além de questões voltadas à aprendizagem, como também necessita considerar a condição que estes se encontram, ou seja, é importante perceber estes sujeitos de maneira ampla, utilizando da interação e de momentos prazerosos para o melhor desenvolvimento dentro dos hospitais.

Procuramos construir um planejamento lúdico, onde o aluno participa, cria objetos, conta e ouve histórias. Não temos um tempo exato de atendimento para cada aluno, ficamos atentas aos sinais, muitas vezes no dia de quimioterapia eles ficam indispostos, uma atividade ou um tempo conversando já é suficiente. E há dias que acordam animados e ansiosos para aprender, onde o tempo passa voando e as 4 ou 5 atividades que preparamos não dão conta e recorremos as atividades extras como massa de modelar, 'contação' de histórias, pinturas com tinta, rodas de conversa, jogos com balões. 


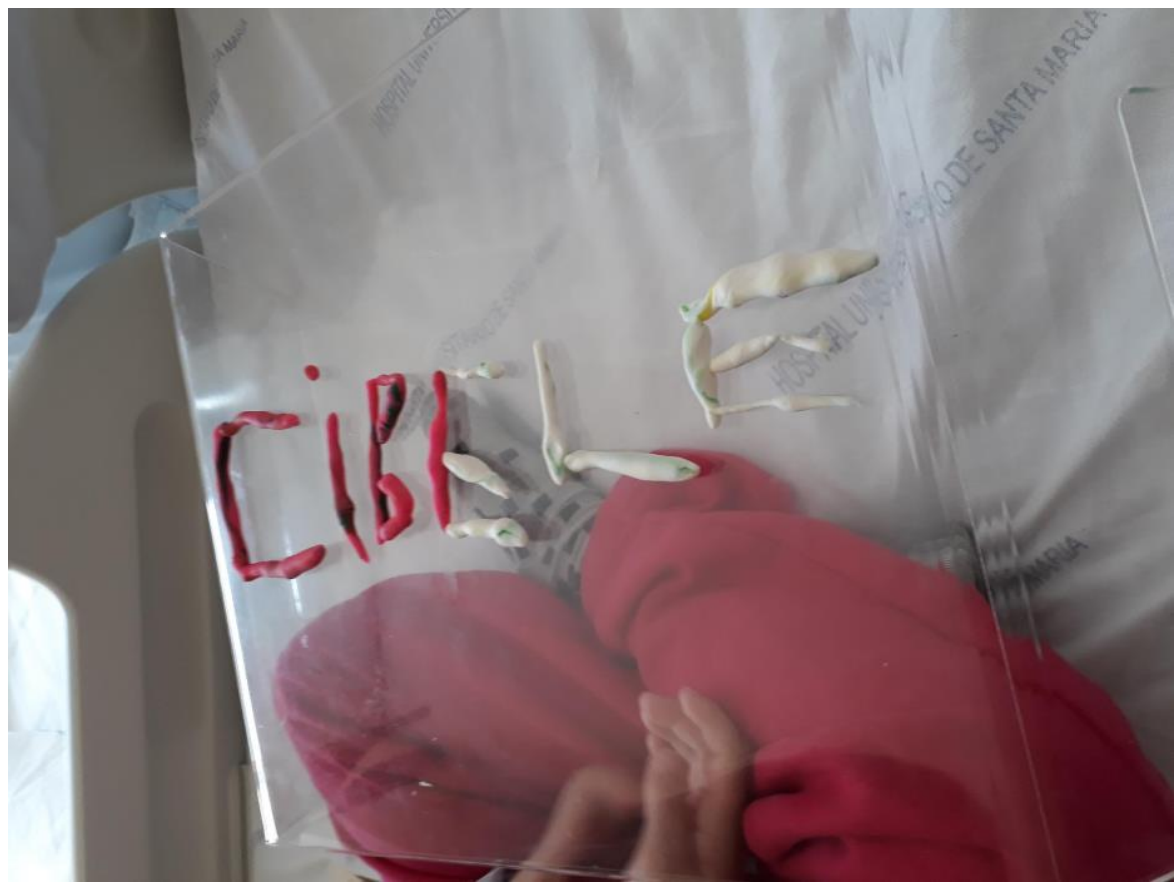

Figura 1 - Trabalhando com massa de modelar.

Fonte: acervo pessoal das autoras.

Como a maior parte do público que atendemos são crianças, é necessário um olhar especial para o 'brincar'. Pensar e possibilitar momentos de brincadeiras sejam livres ou orientadas é essencial para que interajam com os colegas, sempre lembrando as limitações de cada um e mediando as brincadeiras para que sejam saudáveis e adequadas a todos. Normalmente nesses momentos contamos com a ajuda da família para nos movimentarmos até a sala de convivência, espaço onde realizamos atividades para grupos maiores, e ajuda da equipe de enfermagem com a monitoração dos equipamentos.

Apesar do contexto no qual essas crianças e adolescentes estão inseridas, as dificuldades, as situações de tratamento em alguns casos é dolorosa, ainda assim é possível oferecer a esses pacientes uma forma de acompanhamento pedagógico de escolarização, respeitando os limites de cada uma, para que assim o tratamento seja menos doloroso possível, onde por intermédio dos acadêmicos da Licenciatura em pedagogia essas crianças e adolescentes ampliem seu desenvolvimento e a pedagogia hospitalar continue promovendo a aprendizagem nesses ambientes.

Neste aspecto, o propósito da Pedagogia Hospitalar está em propor um local que o conhecimento seja alcançado, de maneira que atenda a criança/adolescente, buscando integrar o doente na situação que se encontra.

As atividades realizadas não têm somente o intuito de distrair o aluno/ paciente de sua realidade, mas também de causar certos tipos de desenvolvimentos que são esperados para 
suas determinadas faixas etárias. Algumas das atividades realizadas e seus propósitos foram: Dia do Peter Pan, em que consistia na "contação" da específica história e posteriormente o aluno jogar um quebra-cabeça de mesmo tema e colorir e rasgar papéis coloridos em pequenos pedaços para colar e preencher o desenho do Peter Pan. Essa atividade contribuiu para aprimorar a motricidade fina; exercitar o raciocínio lógico e despertar a curiosidade do aluno.

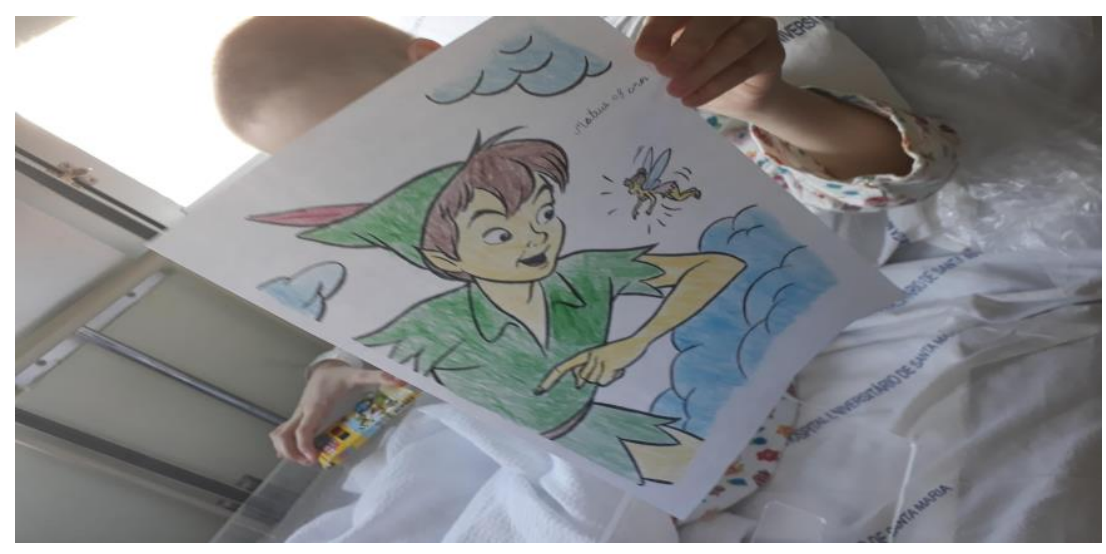

Figura 2 - Colorindo o Peter Pan.

Fonte: acervo pessoal das autoras.

Também foi apresentado aos alunos o jogo "Safari”, que é um jogo de memória com o propósito de treinar a memória; a atenção e a paciência ao esperar a sua vez de jogar.

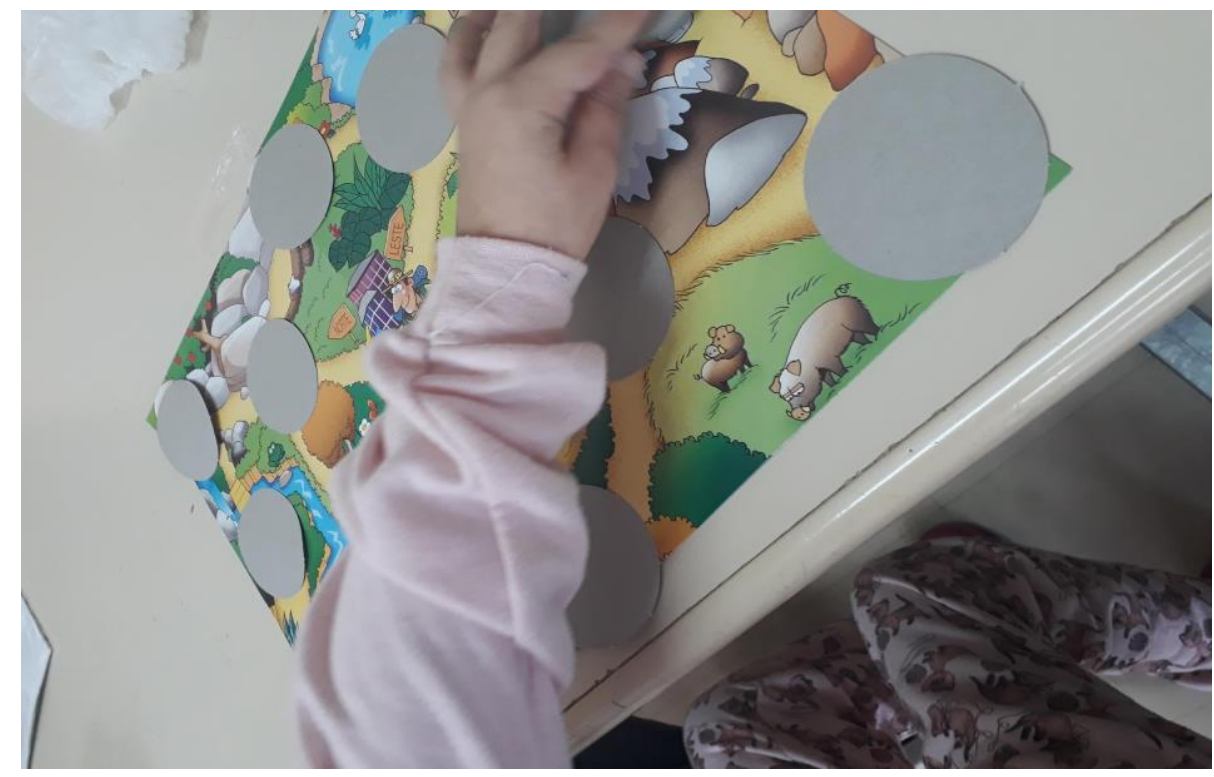

Figura 3 - Jogo Safari.

Fonte: acervo pessoal das autoras. 
Bingo conhecendo os alimentos que consiste em cartelas semelhantes à de bingos, mas com imagens de alimentos (frutas, verduras e legumes) em que as frutas presentes na cartela são sorteadas por uma das graduandas e os alunos tem que marcar a fruta caso ela esteja presente e sua cartela. Esta atividade foi desenvolvida com a intenção de desenvolver a atenção; associar as imagens com as palavras; apresentar as frutas; legumes e verduras os alunos; proporcionar integração e socialização com as orientandas e com os demais participantes da atividade.

\section{Resultados Preliminares Obtidos: o processo de formação/ ação/ hospitalar.}

Compreendemos através das primeiras observações e inserções que é possível desenvolver atividades pedagógicas neste contexto, fugindo da ideia que seremos licenciados/ professores para atuarmos em sala de aula.

A utilização e desenvolvimento de práticas pedagógicas de acordo com a faixa etária dos aluno/sujeitos/pacientes, tendo como pressuposto o acompanhamento dos conteúdos escolares, levando em conta a realidade de cada sujeito também tem sido uma decisão adequada para os estudos no ambiente hospitalar.

O cenário é que não tenhamos disciplinas, atender às características específicas dos sujeitos/pacientes que em geral, não permanecem muito tempo no hospital, apresentam idades e níveis de aprendizagem muito diferenciados e, ainda, são oriundos de diferentes ambientes socioculturais.

É importante destacar a participação dos pais, e demais profissionais da equipe multidisciplinar que atua no hospital, quanto a presença dos acadêmicos no contexto hospitalar.

\section{Contribuições para o contexto investigado e além do contexto hospitalar}

É possível estudar no hospital, pois sujeitos/estudantes/pacientes hospitalizados são beneficiados por este projeto, e a legislação já lhes garante o acesso a este direito. Assim, é pertinente considerar os diretos que respaldam a criança hospitalizada, para então direcionar e auxiliar frente aos desafios encontrados, bem como, agregar meios que favoreçam um melhor desenvolvimento desse sujeito.

Sendo assim, é necessário ter um "olhar" humanizado frente a tais direitos, auxiliando em sua aplicação já é notório que o profissional que atua na Pedagogia hospitalar pode propor maneiras diferentes de mediar o saber entre os sujeitos que estão nestes contextos. 
Dessa maneira será possível aprimorar as capacidades de cada ser, por meio do planejamento, bem como, da análise dos alunos que irá atender, considerando seu contexto e permitindo que a ludicidade tenha espaço neste ambiente. Atuamos na perceptiva de mediador entre a criança com o meio em que está inserido, procurando auxiliá-la de forma que ajude a desenvolver suas potencialidades.

Tal experiência possibilita que tenhamos um olhar voltado para novas possibilidades de atuação profissional. O projeto Institucional Vivencias, no HUSM mediante o subprojeto Educa, Ação, Lúdica Hospitalar, e as intervenções de apoio Pedagógico Hospitalar vislumbra a expansão de ações na rotina institucional em outros espaços que vão além do CTcriaC onde se encontram crianças e adolescentes permanecendo no contexto hospitalar.

Com a concretização destas ações, os acadêmicos, futuros profissionais, poderão cumprir sua formação atuando em outro contexto não escolar de formação. Estas experiências envolvem princípios: Escolar, hospitalar e os da formação acadêmica através das vivências propostas neste contexto educativo.

\section{Referências}

ARAUJO, José Carlos Souza. Disposição da aula: os sujeitos entre a técnica e a polis. In.:VEIGA, Ilma P. (Org.). Aula: Gênese, Dimensões, Princípios e Práticas. Campinas: Papirus, 2008.

BRASIL, Conselho Nacional dos Direitos da Criança e do Adolescente. Resolução n41/1995 de 13 de outubro de 1995. Aprova em sua íntegra o texto oriundo da Sociedade Brasileira de Pediatria, relativa aos Direitos da Criança e do Adolescente hospitalizado. Diário Oficial da República Federativa do Brasil, Brasília (DF); Out 17; Seção 1:163/9-16320, 1995.

BRASIL, Ministério da Educação (BR), Conselho Nacional da Educação. Resolução CNE/ CBE, n. 2, de 11 de setembro de 2001. Diretrizes Nacionais para a Educação Especial na Educação Básica [Internet].Diário Oficial da República Federativa do Brasil, Brasília (DF); 2001.Disponívelem: http://portal.mec.gov.br/arquivos/pdf/resolucao2.pdf. Acesso. 9 junho de 2018.

BRASIL. Ministério da Educação. Classe hospitalar e atendimento pedagógico domiciliar: estratégias e orientações. Secretaria de Educação Especial. Brasília: MEC/ SEESP; 2002.

BRASIL. Conselho Nacional dos Direitos da Criança e do Adolescente. Resolução ${ }^{\circ} 41$ de Outubro de 1995 (DOU 17/19/95). SOUZA et al. 91 ISSN: 1982-1123 Educere - Revista da 
Educação, v. 18, n. 1, p. 81-92, jan./jun. 2018 Carta da criança hospitalizada / Instituto de Apoio à Criança. Humanização dos serviços de atendimento à criança. Lisboa: IAC, 1998. 22 p. ISBN 972-8003-14-5.

CECCIM Ricardo B. Classe hospitalar: encontros da educação e da saúde no ambiente hospitalar. Pátio. 1999.

ESTEVES, C. R. Pedagogia Hospitalar: Um breve histórico, 2008. Disponível em:http://pedagogiaaopedaletra.s3.amazonaws.com/wpcontent/uploads/2013/06/HIST\%C3\% 93RICO-DA-PEDAGOGIA-HOSPITALAR.pdf>.Acesso em: 23 maio 2018.

FONSECA, E. S. A situação brasileira do atendimento pedagógico-educacional hospitalar. Disponívelem:<http://www.scielo.br/scielo.php?script=sci_arttext\&pid=S151797021999000100009>. Acesso em: 25 de maio de 2018.

FREIRE, Paulo. Pedagogia da Autonomia. 39a . ed. São Paulo: Paz e Terra, 1996.

FROEBEL, F. W. A. A educação do homem. Tradução de Maria Helena Câmara Bastos. Passo Fundo: UFP, 2001.

LIMA, C. C. F. e PALEOLOGO, S. O. A. Pedagogia Hospitalar: A importânciado apoio pedagógico dentro dos hospitais para jovens e crianças. Disponível em: <http://www.faceq.edu.br/efaceq/downloads/numero01/pedagogia\%20hospitalar\%20cristina \%20cavallari.pdf>.Acesso em: 21 set 2018.

MAtos, E. L. M. e MUGiATTI, M. M. T. F. Pedagogia Hospitalar: A Humanização Integrando Educação e Saúde. 4. ed. Rio de Janeiro. Ed. Vozes. 2009.

PIMENTA, S. G. Pedagogia e Pedagogos: caminhos e perspectivas. São Paulo: Cortez, 2001.

SILVA, Edileuza F. da.A aula no contextohistórico. In.: In.: VEIGA, Ilma P (Org.). Aula: Gênese, Dimensões, Princípios e Práticas. Campinas: Papirus, 2008.

UNIVERSIDADE FEDERAL DE SANTA MARIA. Centro de Educação. Curso de PedagogiaNoturno.Estrutura do Curso.Disponível>http://pedagogia.noturno.ufsm.br/index.php\#Acesso: 9 de set 2018 . 